\title{
Numerical model for analysis of steel frame structures with included geometric imperfections
}

\author{
Radoslav Markić \\ University of Mostar, Faculty of Civil Engineering, Ph.D C.E. \\ radoslav.markic@gf.sum.ba \\ Dragan Ćubela \\ University of Mostar, Faculty of Civil Engineering, Ph.D C.E. \\ dragan.cubela@gf.sum.ba \\ Željko Mikulić \\ University of Mostar, Faculty of Civil Engineering, B.S.C.E. \\ zeljko.mikulic@gf.sum.ba
}

\begin{abstract}
Numerical model based on finite element method for analysis of steel frame structures is presented. Model is implemented in computer program [9] and implies application of 1D (beam) finite element. Large displacement theory with incremental-iterative solution of equilibrium equations is applied. Application of numerical model is presented on an example of steel frame structure where initial geometric imperfections are also included. It is shown that presented numerical model and computer program [9] can be used for practical design of steel frame structures according to EN 1993-1-1 [10]. Main conclusions are given at the end.
\end{abstract}

Key words: numerical model, 1D beam finite element, steel frame structure, large displacements theory, geometric imperfections

\section{Numerički model za analizu čeličnih okvirnih konstrukcija s uključenim geometrijskim imperfekcijama}

Sažetak: Prikazana je primjena numeričkog modela baziranog na metodi konačnih elemenata za analizu okvirnih konstrukcija izrađenih od čelika. Model je implementiran u računalni program [9] te podrazumijeva primjenu 1D štapnog konačnog elementa pri čemu se jednadžbe ravnoteže zadovoljavaju na deformiranom sustavu (teorija velikih pomaka). $\mathrm{Na}$ primjeru proračuna čeličnog okvira prikazana je mogućnost primjene numeričkog modela sa uzimanjem u obzir početnih geometrijskih imperfekcija. Pokazano je da se implementirani numerički model i računalni program [9] može uspješno koristiti za proračune čeličnih okvirnih konstrukcija prema EN 1993-1-1 [10]. Na kraju su dani komentari sa zaključcima.

Ključne riječi: numerički model, 1D štapni konačni element, čelična okvirna konstrukcija, teorija velikih pomaka, geometrijske imperfekcije 
Markić, R., Ćubela, D., Mikulić, Ž.

Numerical model for analysis of steel frame structures with included geometric imperfections

\section{INTRODUCTION}

Numerical models based on beam 1D finite elements are commonly used for static analyses of load-bearing structures made of beams and columns, most often using linear calculation models (calculations according to first order theory) with a linear material model. Calculation of slender frame structures is a complex engineering problem as they are sensitive to stability loss by buckling and bowing. An adequate numerical model that would include geometric and material nonlinearity, eigenmodes of stability loss, as well as stiffness, rotational capacity and resistance of beam and column joints are crucial for adequate analysis of the behavior of such types of structures. Many scientific and professional papers on this topic have been published so far. Some of them can be found in [1-8].

Paper [1] presents in detail large displacement theory, describing the procedure of two substantially different formulations as part of the geometric nonlinearity analysis. In the total Lagrangian formulation, all static and kinematic variables are referred to the initial geometry at time $\mathrm{t}=0$. In the updated Lagrangian formulation, all static and kinematic variables are referred to the geometry at time t, i.e. the last known geometry. Implementation of equivalent initial local imperfections in the global analysis of steel frames according to Eurocode 3 was analyzed in [2]. Analysis of global and local imperfections in the analysis of frame structures is given in paper [3]. An approach to defining all structural imperfections as a single imperfection, based on an elastic critical form of structural buckling, is presented. A statistical analysis of the reliability of the calculation of steel frames according to Eurocode 3 was conducted in paper [4], taking into account the coincidence of the initial imperfections with the eigenmode of stability loss by buckling. Numerical analysis involved the application of geometrically nonlinear analysis of steel frames with initial imperfections. The analysis results indicated the problem of inconsistencies in the field of calculation reliability according to Eurocode 3. The author proposes to increase the initial imperfections in relation to the recommendations from Eurocode 3 in order to improve the reliability in the calculation. The problems of calculation of slender steel structures sensitive to flexural and torsional buckling is treated in paper [5]. Principles and application of unique equivalent global and local imperfections in the analysis of steel frame structures in combination with elastic critical forms of buckling in accordance with the standard EN 1993-1-1: 2005, 5.3.2(11) are discussed in paper [6]. Paper [7] is a continuation of paper [6] and it presents the problems of global and local imperfections in elements of steel structures (variable sections by length, arched structures with mutually inclined arches) where methods according to the standard EN1993-1-1:2005 are not applicable. The linear elastic bifurcation (eigenvalue) analysis with the calculation of the elastic critical force and effective buckling length were analyzed in [8]. In the paper, the numerical model [9] is verified in relation to another computer program and using simple examples for which solutions can be exactly determined. It is shown that the mutual variations between the two computer programs are up to $5 \%$, which indicates a rather high accuracy for the purposes of structural analyses.

Previously developed numerical model of geometric nonlinearity for large displacement problems, implemented in a computer program [9], is presented as part of this paper. Methods of global analysis of steel structures according to EN 1993-1-1 [10] are described, explaining in more detail the procedures of accounting for geometric imperfections in analyses of steel frame structures. Application of the computer program [9] is presented on a practical example of the calculation of a steel frame with geometric imperfections taken into consideration according to EN 1993-1-1 [10]. 
Markić, R., Ćubela, D., Mikulić, Ž.

Numerical model for analysis of steel frame structures with included geometric imperfections

\section{NUMERICAL MODEL OF LARGE DISPLACEMENTS}

This paper presents a previously developed model of geometric nonlinearity for large displacements, small strains problem as part of a nonlinear analysis of structures modeled by beam 1D ideally straight finite elements, with constant cross-section and with two nodes per element. Each node has 6 degrees of freedom (3 displacements and 3 rotations). Figure 1 shows a graphical representation of the numerical model with 1D beam elements, where the material model is linear. The numerical model is implemented in the computer program [9], in which it is presented in more detail. The numerical model also includes the effect of structural deformation on the increase of internal forces, which is especially pronounced in slender structures sensitive to stability loss by buckling.

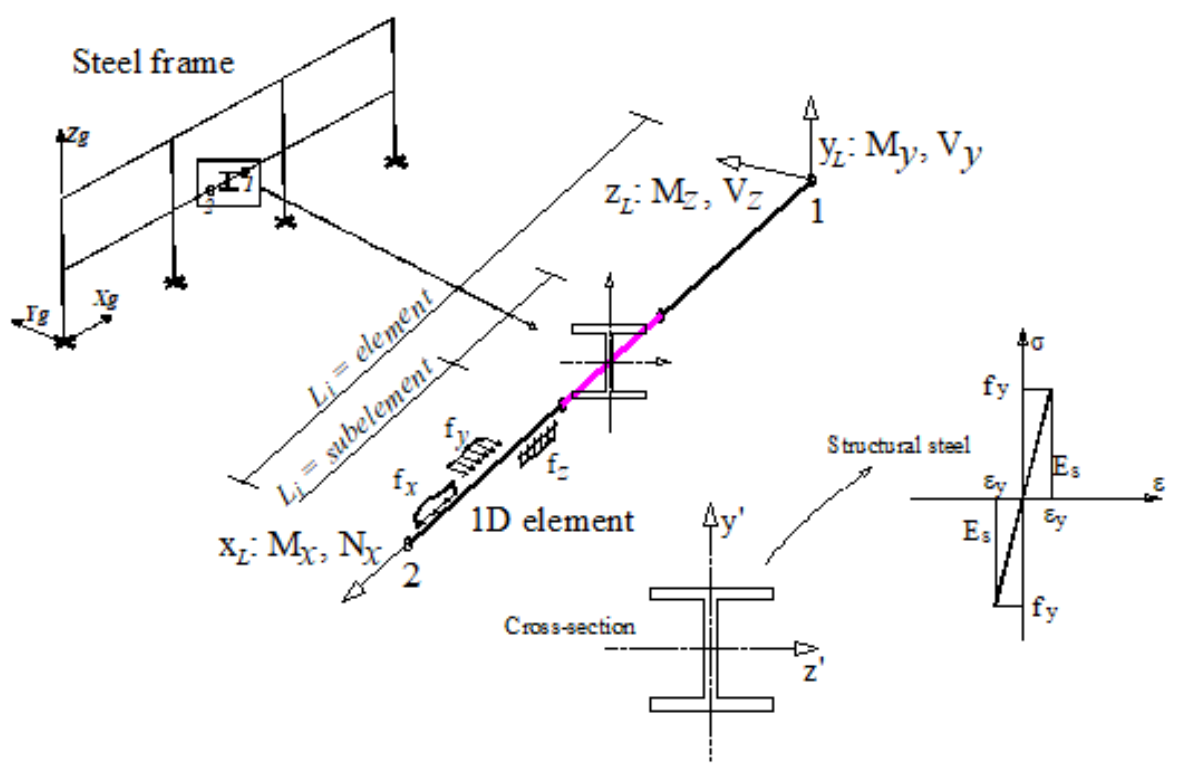

Figure 1. Graphical representation of the numerical model with 1D beam elements within [9]

The so-called updated Lagrange formulation was used to solve the problem. The external load is set in increments and for each load increment an iterative calculation procedure is performed until the vector of unbalanced forces is within the given tolerance limits, i.e. until the balance of external and internal forces is established. Once the convergence criterion is met, the unbalanced forces vector is added to the next external load increment and the iterative procedure continues again. At the end of each iteration step, the state of variables is updated with respect to the geometry at time $t$, i.e., to the last known geometry. Equilibrium equations become nonlinear considering that the geometry is established to the last known geometry. The principle of superposition of effects does not apply in this case. The relationship between deformations and displacements is linear, since the displacement increment within each iteration step is small. This approach significantly simplifies and shortens the calculation.

The full Newton-Raphson iteration method is used to solve the system of nonlinear equations. Figure 2 shows this method. 


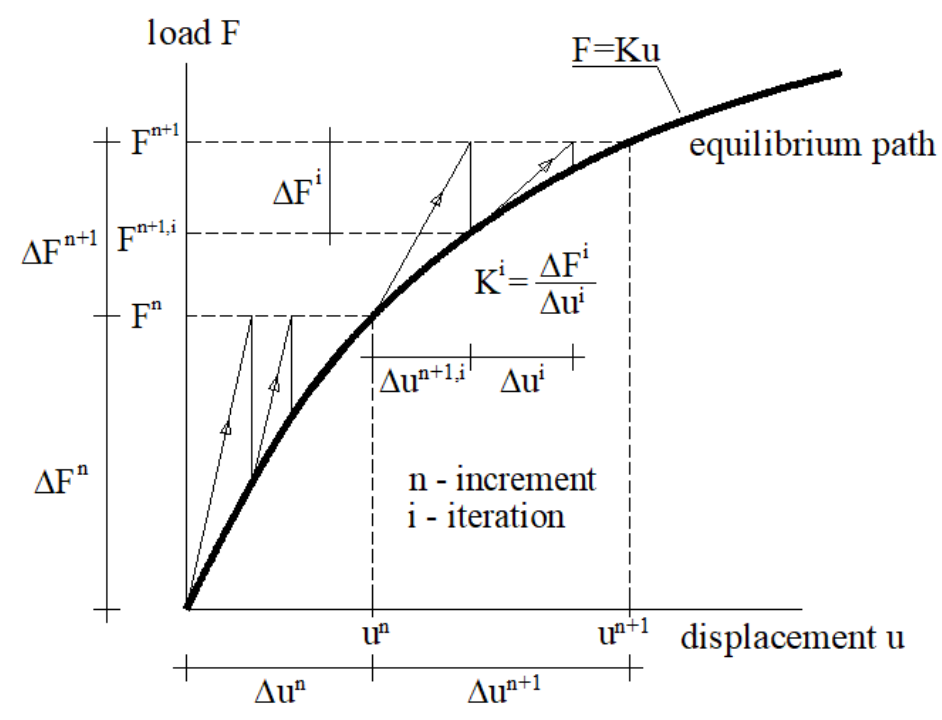

Figure 2. Newton-Raphson method

The stiffness matrix is calculated in the computer program for each load increment and defined iteration step i. In each iteration step, to find solution of the problem, the following system is solved:

$$
\mathrm{K}^{\mathrm{i}} \Delta \mathrm{u}^{\mathrm{i}}=\mathrm{F}^{\mathrm{n}+1}-\Delta \mathrm{F}^{\mathrm{i}}
$$

where $\mathrm{n}$ is the observed increment in the iteration step $\mathrm{i} ; \mathrm{K}^{\mathrm{i}}$ is the current tangent stiffness matrix of the structure and geometric nonlinearity (large displacements, small deformations); $\Delta \mathrm{u}^{\mathrm{i}}$ is the current displacement increment; $\mathrm{F}^{\mathrm{n}+1}$ is the current vector of external nodal forces and $\Delta \mathrm{F}^{\mathrm{i}}$ is the current vector of internal nodal forces due to material stress. The iteration process is continued until the current vector of unbalanced forces $\left(\mathrm{F}^{\mathrm{n}+1}-\Delta \mathrm{F}^{\mathrm{n}+1, \mathrm{i}}\right)$ is suitably small enough. Then the vector of unbalanced forces is added to the new external load increment and the iteration process is repeated again. One should observe the difference between the computational solving method and the real way to the solution since the exact way to the solution is not known, that is, the solution is with a certain error in the last iteration step depending on the selected convergence criterion. It is necessary to take sufficiently small load increments, depending on the problem being considered, in order to prevent "sidestepping" the actual way, which can produce non-existent nonlinearities. The size of the load increment has an impact on the obtained results and the more significant this impact is the higher the degree of nonlinearity. Smaller load increments should normally give more accurate results. In some cases with a very marked geometry change, it is possible that this method does not give a solution.

\section{GLOBAL ANALYSIS METHOD ACCORDING TO EUROCODE 3}

According to EN 1993-1-1[10], calculation of steel frame structures must be based on structural design models appropriate to the considered limit state. In the process, the structural design must include a proof of the ultimate limit state (ULS) and the serviceability limit state (SLS). 
Markić, R., Ćubela, D., Mikulić, Ž.

Numerical model for analysis of steel frame structures with included geometric imperfections

The same standard also specifies that the design model and basic design assumptions should reflect the behavior of the structure in the relevant limit state with adequate accuracy and the expected type of behavior of cross sections, elements, connections and bearings.

According to EN 1993-1-1[10] the global calculation of internal forces and bending moments may be determined according to:

- Calculation according to the first order theory using the initial geometric shape of the structure or

- Calculation according to the second order theory, taking into account the influence of the deformation of the structure.

In general, methods of structural analysis can be divided into linear and nonlinear. Nonlinear analysis means material and geometric nonlinearity. Considering the complexity of nonlinear calculation methods, it is inevitable to use numerical models that can cover all these effects. Figure 3 shows a schematic load - displacement relation depending on the selected frame calculation method.

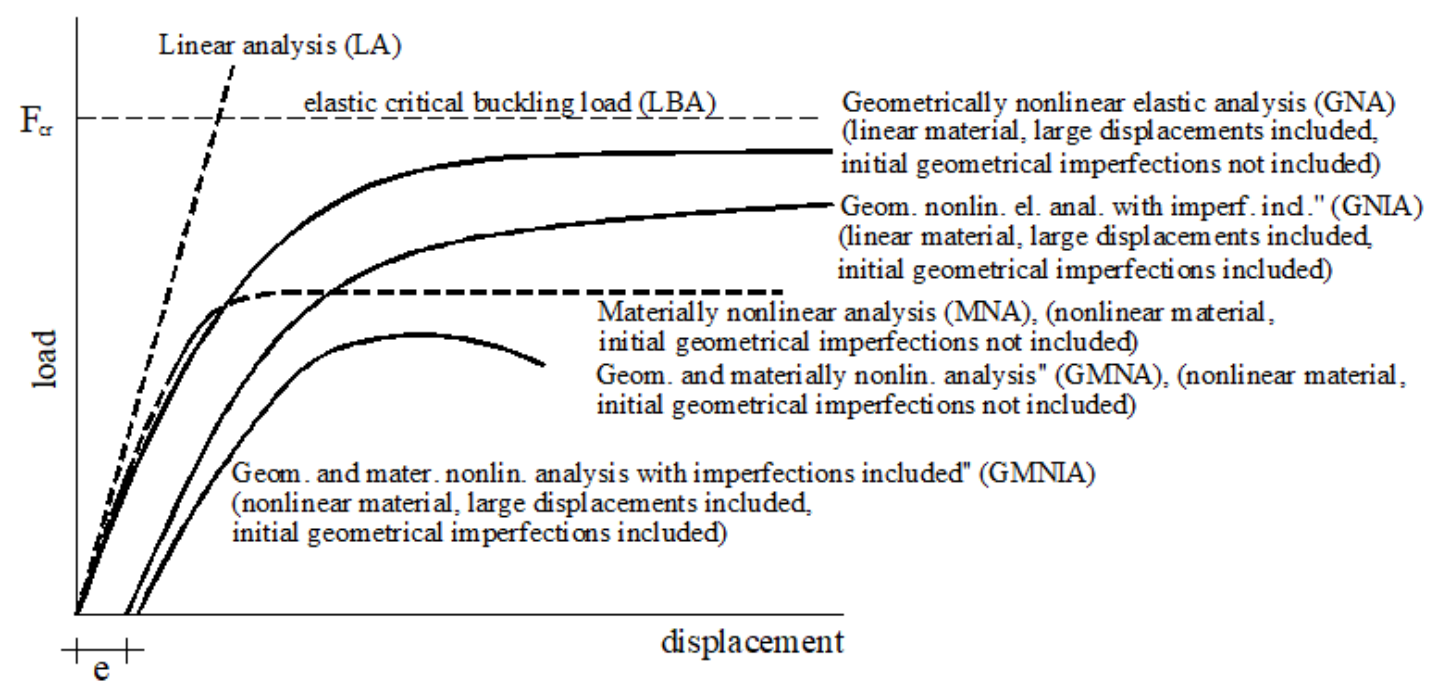

Figure 3. Load - displacement relation depending on the selected frame calculation method

Linear analysis (LA) is a calculation based on linear elastic theory, associated with an ideal shape of the structure. Linear elastic bifurcation (eigenvalue) analysis (LBA) is a calculation of the eigenvalues (vibration modes) of a structure based on linear elastic theory. Geometrically nonlinear elastic analysis (GNA) is a calculation based on large displacement theory (includes the influence of the deformation of the structure on internal forces and bending moments without taking into account the initial imperfections in the structure) and implies a linear elastic material model. Elastic critical force control is included in each load level.

Geometrically nonlinear elastic analysis with imperfections included (GNIA) is a calculation based on large displacement theory (includes the influence of the deformation of the structure on internal forces and bending moments with initial imperfections in the structure) and implies linear elastic material model. Elastic critical force control is included in each load level.

Materially nonlinear analysis without taking into account the initial imperfections (MNA) is a calculation based on linear elastic theory and implies a nonlinear material model (elastoplastic, plastic, arbitrary). If large displacement theory is included, the method 
becomes geometrically and materially nonlinear analysis (GMNA). It is then a calculation based on large displacement theory (includes the influence of the deformation of the structure on internal forces and bending moments but without initial imperfections in the structure) with a nonlinear model of material (elastoplastic, plastic, arbitrary). Elastic critical force control is included in each load level.

Geometrically and materially nonlinear analysis with imperfections included (GMNIA) is a calculation based on large displacement theory (includes the influence of the deformation of the structure on internal forces and bending moments with initial imperfections in the structure) with a nonlinear material model (elastoplastic, plastic, arbitrary). Elastic critical force control is included in each load level.

Selecting the appropriate method is a complex task and depends on the type of structure and the available numerical model. To select a calculation method, it is necessary primarily to assess whether the effects of structural deformation have an influence on the overall behavior of the structure under load and what the effects of applying the selected method are.

As the complexity and accuracy of the methods increases, they require more and more input data on which the accuracy of the obtained results depends. Therefore, when selecting a calculation method, it is necessary to make sure that the method is adequate to the problem and that the computer program is reliable.

Application of the presented numerical model within the computer program [9] for the analysis of steel frame structures using the method of geometrically nonlinear elastic analysis with imperfections included (GNIA) will be analyzed as part of this paper. The calculation includes the calculation of internal forces and bending moments according to the large displacement theory (includes the influence of the deformation of the structure on internal forces and bending moments with initial imperfections in the structure). A linear elastic model of steel will be adopted in the model considering that the method is materially linear.

In accordance with EN 1993-1-1, part 5.1.2 [10] the effects of the behavior of joints on the distribution of internal forces and moments within a structure, and on the overall deformations of the structure, may generally be neglected, but where such effects are significant (such as in the case of semi-continuous joints) they should be taken into account, according to EN 1993-1-8 [11].

The "GNIA" method is a materially linear analysis and according to EN 1993-1-8, part 5.1.1 [11] joints in the global calculation can be defined as nominally pinned (do not transmit bending moments), rigid (transmit bending moments) and semi-rigid (partially transmit bending moments) defined by rotational stiffness according to EN 1993-1-8, section 5.1.2 [11].

Rigid and hinged joints will be applied in the example of steel frame calculation in [9].

The calculation procedure by the method of geometrically nonlinear elastic analysis with imperfections included can be applied irrespective of the sensitivity of the structure to stability loss by buckling, with the standard EN 1993-1-1, part 5.2.2 [10] specifically requiring application of more accurate methods that include initial imperfections and the influence of structural deformation on internal forces and bending moments, for the case $\alpha_{\mathrm{cr}}<3$. If $\alpha_{\mathrm{cr}} \geq 10$, the calculation of forces according to the theory of elasticity can be applied, and if $\alpha_{c r} \geq 15$, the calculation of forces according to the theory of plasticity can be applied. This indicates that the higher the value of the coefficient $\alpha_{c r} i$ is, the less sensitive to stability loss by bending the structure is.

Figure 4 shows the calculation procedure by the "GNIA" method within the computer program [9] and the diagram of global and local imperfections. 


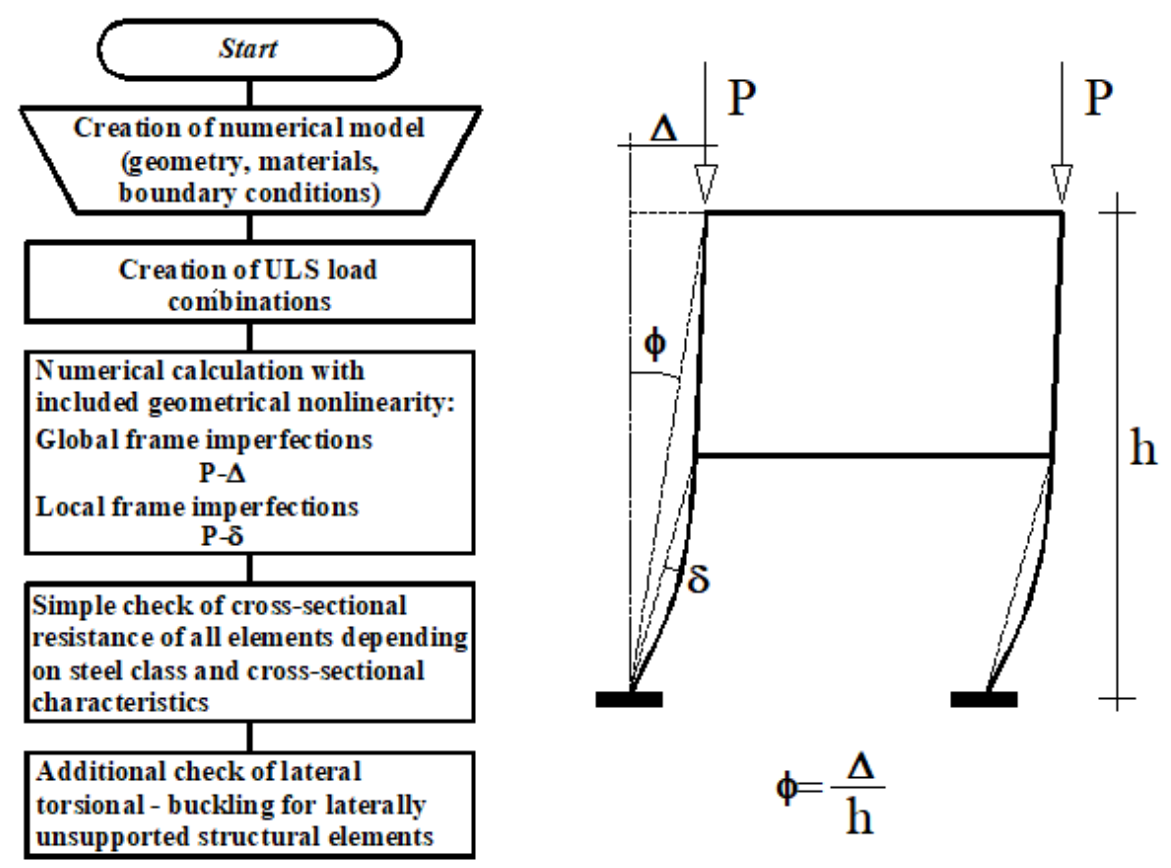

Figure 4. Procedure for calculation of steel frames using the GNIA method (geometrically nonlinear elastic analysis with included imperfections $\mathrm{P}-\Delta$ and $\mathrm{P}-\delta$ ) in [9]

The elastic critical load factor $\alpha_{c r}$ is the factor which, when multiplied by the design load (longitudinal compressive force in the element of all ULS combinations), gives the value that causes elastic buckling of the structure. Essentially, it is the smallest longitudinal compressive force that causes elastic instability. It is defined by the expression:

$$
\alpha_{\mathrm{cr}}=\frac{\mathrm{F}_{\mathrm{cr}}}{\mathrm{F}_{\mathrm{Ed}}}
$$

where

$\mathrm{F}_{\mathrm{Ed}}$ is the design longitudinal compressive force determined by calculation for all ULS load combinations

$\mathrm{F}_{\mathrm{cr}}$ is Euler's critical buckling force

$$
\mathrm{F}_{\mathrm{cr}}=\frac{\mathrm{EI \pi ^{2 }}}{\mathrm{L}_{\mathrm{i}}^{2}}
$$

Based on the known Euler's critical buckling force $\mathrm{F}_{\mathrm{cr}}$, the effective buckling length $\mathrm{L}_{\mathrm{i}}$ can be calculated according to expression (3). The same is often used as input data for the calculation of buckling resistance of members according to the conventional expressions from EN 1993-1-1 [10].

$$
L_{i}=\sqrt{\frac{E I \pi^{2}}{N_{c r}}}
$$

In the computer program [9], the problem of elastic critical buckling and the calculation of the $\alpha_{\mathrm{cr}}$ factor are solved by a linear elastic bifurcation (eigenvalue) analysis (LBA). 
Markić, R., Ćubela, D., Mikulić, Ž.

Numerical model for analysis of steel frame structures with included geometric imperfections

Considering that the structure has multiple eigenvalues, the lowest values of the factor $\alpha_{c r}$ are determined by calculation. It is certainly suggested to analyze several modes, which depends on the complexity of the structure, considering that local modes can vibrate. In paper [8], the numerical model implemented in [9] is described and tested in more detail.

Global imperfections ( $\mathrm{P}-\Delta$ effects) are related to frame imperfections. The assumed form of global imperfections can be obtained from the elastic mode of structural buckling in the observed direction, while taking account of the effects of deformation of the frame as a whole on internal forces and bending moments. Standard EN 1993-1-1, part 5.3.2a) [10] defines that the effect of imperfection should be included in the calculation of the frame in the form of an initial transverse displacement. Global initial imperfection due to transverse displacement is defined by the expression:

$$
\phi=\phi_{0} \cdot \alpha_{\mathrm{h}} \cdot \alpha_{\mathrm{m}}
$$

where:

$\phi_{0}=1 / 200=0.005$ is the basic value

$\alpha_{\mathrm{h}}=\frac{2}{\sqrt{\mathrm{h}}}$ but $\frac{2}{3} \leq \alpha_{\mathrm{h}} \leq 1, \mathrm{~h}$ - height of the structure in meters

$\alpha_{\mathrm{m}}=\sqrt{0.5\left(1+\frac{1}{\mathrm{~m}}\right)}$ reduction factor for the number of columns in a row

$\mathrm{m}$ - is the number of columns in a row including only those columns which carry a vertical load $F_{E d}$ not less than $50 \%$ of the average value of the column in the observed plane

Local imperfections ( $\mathrm{P}-\delta$ effects) are related to element imperfections. The effects of local deformation of the element due to the change in stiffness of the loaded element have an influence on internal forces and bending moments. The element subjected to tension has an increased stiffness and a reduced stiffness in compression, where the individual bows of elements according to EN 1993-1-1, part 5.3.2b) [10] are taken as relative initial imperfections due to bow of the elements for flexural buckling according to the expression:

$$
\mathrm{e}_{\mathrm{o}} / \mathrm{L}
$$

where:

$L-$ is the length of the element

The recommended design values of local imperfections due to bow of elements $\mathrm{e}_{\mathrm{o}} / \mathrm{L}$ are given in Table 1 according to EN 1993-1-1, part 5.3.2b) [10].

Table 1. The recommended design values of local imperfections due to bow of elements $e_{o} / L$

\begin{tabular}{|c|c|c|}
\hline Buckling curve in & Elastic calculation & Plastic calculation \\
\cline { 2 - 3 } accordance with EC3 & $\mathrm{e}_{\mathrm{o}} / \mathrm{L}$ & $\mathrm{e}_{\mathrm{o}} / \mathrm{L}$ \\
\hline $\mathrm{a}_{\mathrm{o}}$ & $1 / 350$ & $1 / 300$ \\
\hline $\mathrm{a}$ & $1 / 300$ & $1 / 250$ \\
\hline $\mathrm{b}$ & $1 / 250$ & $1 / 200$ \\
\hline $\mathrm{c}$ & $1 / 200$ & $1 / 150$ \\
\hline $\mathrm{s}$ & $1 / 150$ & $1 / 100$ \\
\hline
\end{tabular}

The calculation conducted by the method of geometrically nonlinear elastic analysis with global and local imperfections included is followed by a simple verification of the resistance of cross-sections of all elements depending on the steel class and cross-sectional characteristics. Consistent with EN 1993-1-1, part 5.2.2.(7)a) [10] if the effects of deformation of the structure 
(the standard specifies the second order effects) and the corresponding imperfections for individual elements are taken into account in the global analysis, in that case no individual stability check of the elements according to paragraph 6.3, EN 1993-1-1 [10] is necessary.

In that case, the cross-sectional resistance check is controlled according to the following expression:

$$
\frac{N_{E d}}{N_{R d}}+\frac{M_{y, E d}}{M_{y, R d}}+\frac{M_{z, E d}}{M_{z, R d}} \leq 1
$$

where

$\mathrm{N}_{\mathrm{Ed}}, \mathrm{M}_{\mathrm{y}, \mathrm{Ed}}, \mathrm{M}_{\mathrm{z}, \mathrm{Ed}}$ are the calculation values of longitudinal force and bending moments about the $y$ and $z$ axes, calculated in global analysis

$\mathrm{M}_{\mathrm{y}, \mathrm{Rd}}, \mathrm{M}_{\mathrm{z}, \mathrm{Rd}}$ are the calculation values of resistance

EN 1993-1-1, part 5.2.2.(7)b) [10] also specifies that for individual elements and certain individual imperfections that are not accounted for in the global analysis, additional control is required. Thus, if the control of lateral torsional buckling for laterally unsupported structural elements is not taken in the global analysis, the same should be checked in conformity with the provisions of EN 1993-1-1 [10].

The same holds for the initial local imperfections of the element, if they are not accounted for, additional check of a separated member for the effects of buckling is required.

\section{EXAMPLE}

The numerical model and computer program [9] were tested on the example of calculation of a steel two-hinged frame with a straight crossbar in Figure 5, taken from [12]. The height of the steel frame is $H=6 \mathrm{~m}$, its span is $\mathrm{L}=8 \mathrm{~m}$. It is subjected to horizontal and vertical design loads. S355 class structural steel was adopted. The columns are hinge-supported at the bottom, and the joint between the crossbar (beam) and the column is rigid.

First, classification of the frame was performed by calculating the elastic critical load factor $\alpha_{\mathrm{cr}}$. Considering that the problem of elastic critical buckling and calculation of the $\alpha_{\mathrm{cr}}$ factor are solved in the computer program [9] by linear elastic bifurcation (eigenvalue) analysis (LBA), calculation of the $\alpha_{\text {cr }}$ factor is given for the first two modes.

Then, the calculation of internal forces and the coefficient of utilization of columns are presented with respect to two different modeling approaches.

Model 1 is a materially linear model. The steel frame columns will be dimensioned for internal forces determined by the elasticity theory method ("LA" method) where the individual stability check of the elements is performed in accordance with part 6.3, EN 1993-1-1 [10].

Model 2 is also a materially linear model. The frame columns will be dimensioned for internal forces determined by the GNIA method (geometrically nonlinear elastic analysis with global and local imperfections included) taking into account the calculation according to the large displacement theory presented in part 2 and implemented in [9]. In this case, the check of cross-sectional resistance is reduced to satisfying expression (8). The initial global and local imperfections will be defined by the expressions from EN 1993-1-1, part 5.3.2 a) and b) [10].

In both models and approaches, control of lateral torsional buckling for laterally unsupported structural elements is not taken into account. The results of the analyses are given below in Figures 6-7. 


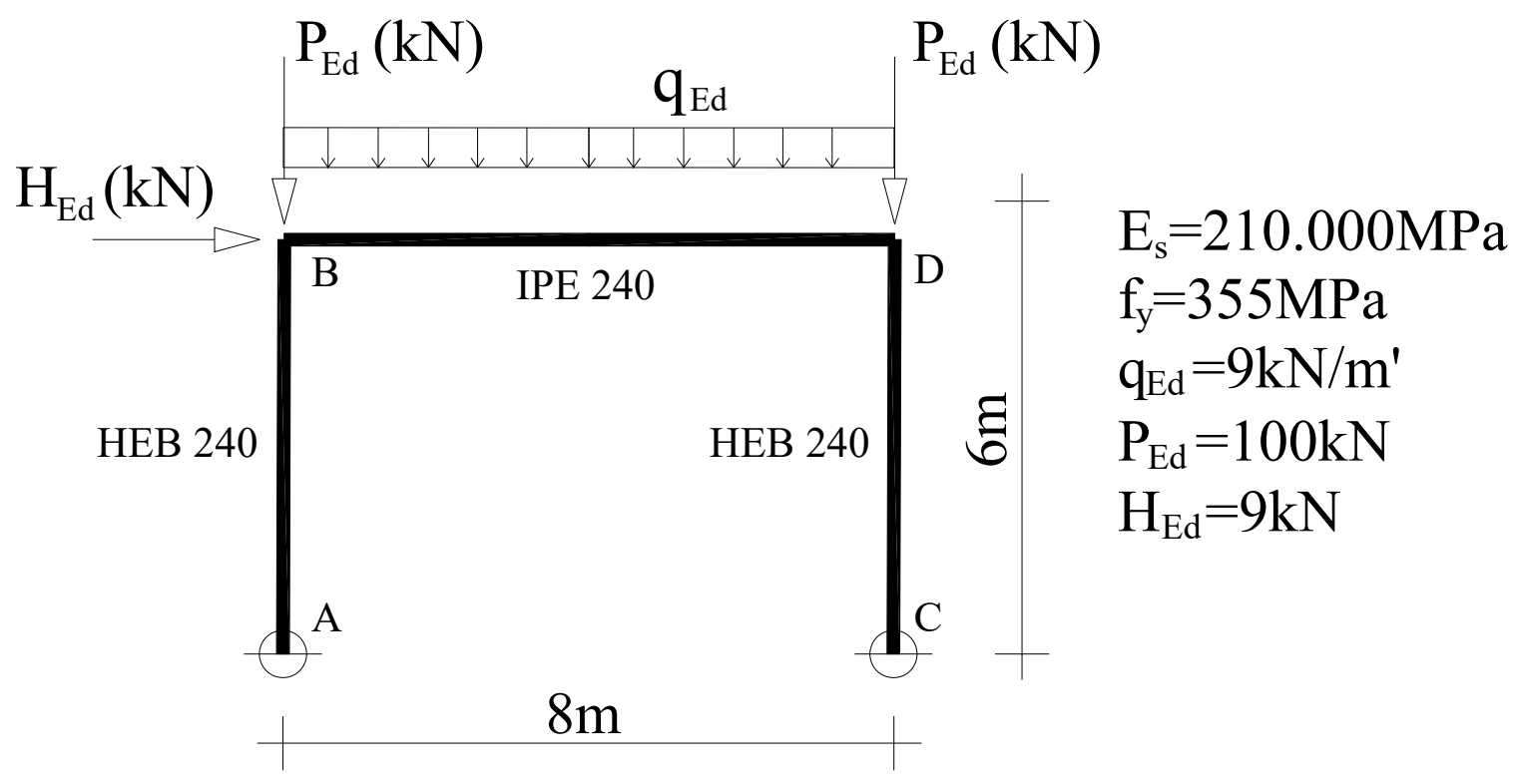

Figure 5. Steel frame taken from [12]

The classification of frame movability was performed in the calculation model [9], and the results are presented in Figure 6.

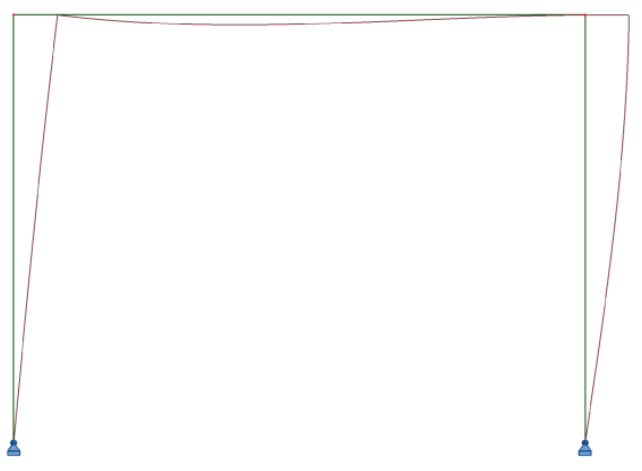

Mode 1

Column A-B

$\alpha_{c r}=4.675 ; F_{c r}=621.65 \mathrm{kN} ; L_{\mathrm{i}}=19.38 \mathrm{~m}$

Column C-D

$\alpha_{\text {cr }}=4.675 ; \mathrm{F}_{\mathrm{cr}}=688 \mathrm{kN} ; \mathrm{L}_{\mathrm{i}}=18.42 \mathrm{~m}$

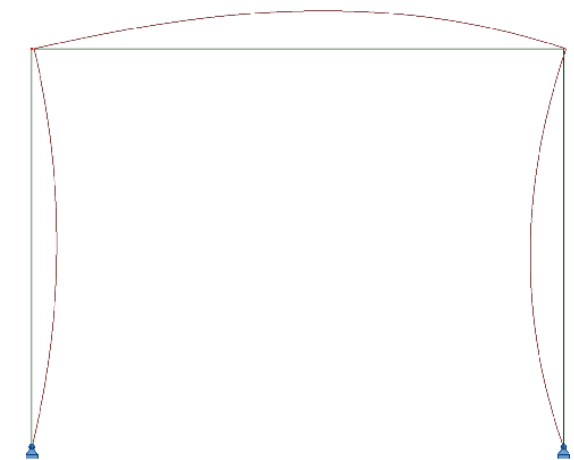

Mode 2

Column A-B

$\alpha_{\text {cr }}=59.55 ; \mathrm{F}_{\mathrm{cr}}=7948.80 \mathrm{kN} ; \mathrm{L}_{\mathrm{i}}=5.42 \mathrm{~m}$

Column C-D

$\alpha_{\text {cr }}=59.55 ; F_{\text {cr }}=8765.83 \mathrm{kN} ; L_{\mathrm{i}}=5.16 \mathrm{~m}$

Figure 6. Calculation of the elastic critical load factor $\alpha_{\mathrm{cr}}$ in [9] for the first two modes

The first mode that gives the lowest value of $\alpha_{\mathrm{cr}}$ is relevant.

The calculation showed that $\alpha_{\mathrm{cr}}=4.675<10$. The frame is movable and the geometric imperfections of the frame should be taken into account. 
Markić, R., Ćubela, D., Mikulić, Ž.

Numerical model for analysis of steel frame structures with included geometric imperfections

Global geometric imperfections will be taken into account in models 1 and 2 . Local imperfections in model 1 should be taken as part of the buckling resistance calculation according to EN 1993-1-1, section 6.3 [10]. Local imperfections in model 2 will be taken directly in the model by setting the initial local imperfection of the member depending on the buckling curve that corresponds to the steel cross section, and in the direction of the dominant mode of the observed direction (in this case mode 1).

Global frame imperfections are:

$\phi=\phi_{0} \cdot \alpha_{\mathrm{h}} \cdot \alpha_{\mathrm{m}}=\frac{1}{200} \cdot 0.816 \cdot 0.866=\frac{1}{200} \cdot 0.707$

$\phi_{0}=1 / 200=0.005$

$\alpha_{\mathrm{h}}=\frac{2}{\sqrt{\mathrm{h}}}=\frac{2}{\sqrt{6}}=0.816, \frac{2}{3} \leq \alpha_{\mathrm{h}}=0.816 \leq 1$

$\alpha_{\mathrm{m}}=\sqrt{0.5\left(1+\frac{1}{\mathrm{~m}}\right)}=\sqrt{0.5\left(1+\frac{1}{2}\right)}=0.866$

$\mathrm{H}_{\mathrm{d}}=9 \mathrm{kN}<0.15 \cdot \mathrm{V}_{\mathrm{Ed}}=0.15 \cdot 272 \mathrm{kN}=40.8 \mathrm{kN} \ldots$ global imperfections must not be neglected

Equivalent horizontal force

$\Delta \mathrm{H}_{\mathrm{Ed}}=\phi \cdot \mathrm{V}_{\mathrm{Ed}}=\frac{1}{200} \cdot 0.707 \cdot\left(8 \mathrm{~m} \cdot 9 \frac{\mathrm{kN}}{\mathrm{m}^{\prime}}+2 \cdot 100 \mathrm{kN}\right)=\frac{1}{200} \cdot 0.707 \cdot 272 \mathrm{kN}=0.961 \mathrm{kN}$

$\Delta \mathrm{H}_{\mathrm{d}}=\mathrm{H}_{\mathrm{Ed}}+\Delta \mathrm{H}_{\mathrm{Ed}}=9 \mathrm{kN}+0.961 \mathrm{kN}=9.961 \mathrm{kN}$

The relative initial imperfections due to bow of the elements for flexural buckling will be taken into account in model 2 through the local imperfection of the column.

Column HEB 240 - buckling curve in accordance with EC3 (Table 6.2) is "a".

$\mathrm{e}_{\mathrm{o}} / \mathrm{L}=1 / 300$

Imperfection of the column with height $L=600 \mathrm{~cm}$ is $\mathrm{e}_{\mathrm{o}}=2 \mathrm{~cm}$, and it can be assigned to each column as an equivalent (replacement) line load in the observed horizontal direction according to the expression from EC3:

$\mathrm{q}_{\mathrm{Ed}}=\frac{8 \cdot \mathrm{F}_{\mathrm{Ed}} \cdot \mathrm{e}_{0}}{\mathrm{~L}^{2}}$, where $\mathrm{F}_{\mathrm{Ed}}-$ is the design longitudinal force, $\mathrm{L}-$ length of the element

Figure 7 shows the bending moments from model 1 and model 2 . The loads are according to Figure 5, except that the force $H_{d}$ is replaced by the force $\Delta H_{d}$. In model 2, the local imperfections of columns in the direction of mode 1 are also taken into account. 
Markić, R., Ćubela, D., Mikulić, Ž.

Numerical model for analysis of steel frame structures with included geometric imperfections

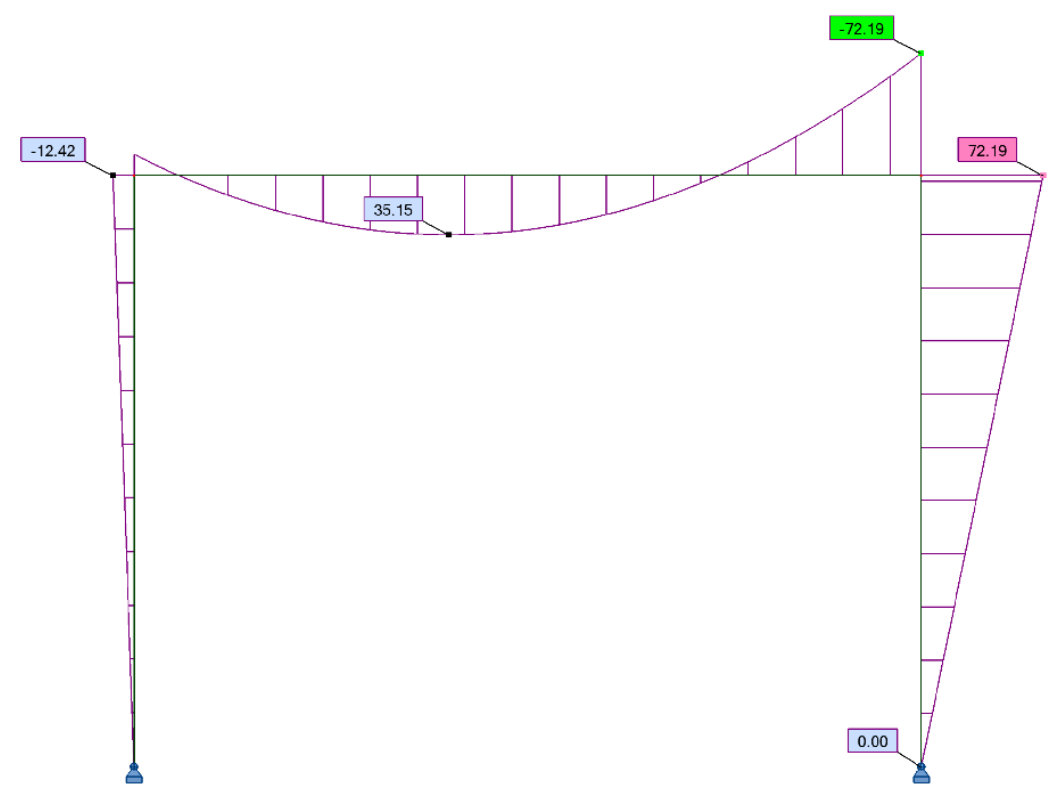

Model 1 - linear model

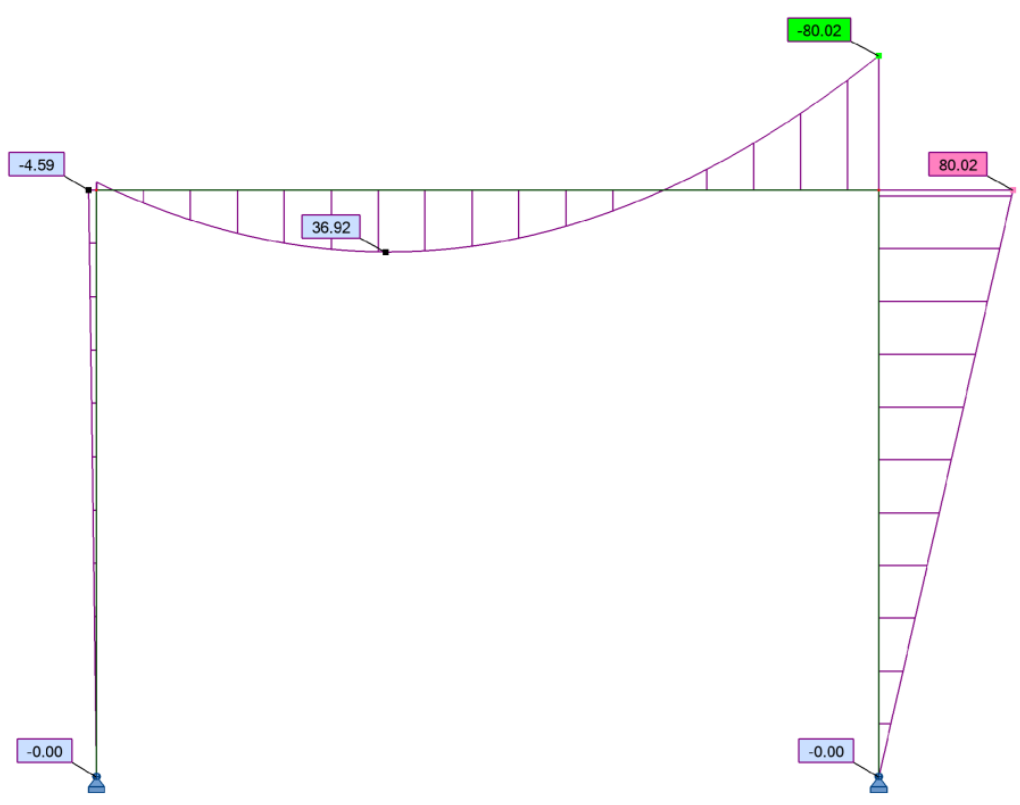

Model 2 - "GNIA" model

Figure 7. Bending moments $M_{E d}(k N m)$ according to models 1 and 2

The calculation of resistance of model 1 columns was performed according to EN 1993$1-1$, part 6.3 [10] where buckling lengths were adopted according to the calculation of the first mode.

The calculation of resistance of model 2 columns was performed according to expression (8), considering that the global and local imperfections of the frame were taken into account, and the calculation was performed by the large displacement method.

Table 2 shows the coefficients of utilization of columns HEB 240 calculated according to models 1 and 2 . 
Markić, R., Ćubela, D., Mikulić, Ž.

Numerical model for analysis of steel frame structures with included geometric imperfections

Table 2. Coefficients of utilization of columns HEB 240 according to models 1 and 2

\begin{tabular}{|c|c|c|}
\hline $\begin{array}{c}\text { Column HEB } \\
240\end{array}$ & $\begin{array}{c}\text { Model 1 } \\
\text { Resistance according to part 6.3 } \\
(\text { EC3) }\end{array}$ & $\begin{array}{c}\text { Model 2 } \\
\text { Resistance according to expression } \\
(8)\end{array}$ \\
\hline A - B & 0.271 & 0.046 \\
\hline B - C & 0.404 & 0.253 \\
\hline
\end{tabular}

Linear analysis with the conventional approach of calculating the resistance of elements on a "separated member" gave higher utilization coefficients, which indicates that the "conventional" calculation is conservative, but it is often uneconomical.

The GNIA method gave more rational values of utilization coefficient, which indicates the advantages of applying such method because the reduction coefficients due to buckling in the calculation are taken $\chi=1.0$. The difference in utilization coefficients is considerable, however it all depends on the specific case and depends on several parameters (load levels, cross sections, boundary conditions and the like).

\section{CONCLUSIONS}

This paper presents a previously developed numerical model implemented in the computer program [9] for problems with pronounced geometric nonlinearity effects, which are particularly present in steel frame structures. 1D beam finite elements are used in the model and equilibrium equations are satisfied on a deformed system (large displacement theory).

Application of geometrically nonlinear analysis is crucial for all structures that are sensitive to changes in geometry under load (steel frames, cables, etc.).

Applicability of the numerical model and the computer program [9] is shown on the example of a steel frame, with initial geometric imperfections taken into consideration. Two different steel frame calculation models were analyzed in the process. Model 1 is based on linear elastic theory ("LA" method), where global frame imperfections can be taken as replacement horizontal loads, and local member imperfections are taken through the buckling resistance proof procedure. Model 2 is based on large displacement method, i.e. geometrically nonlinear elastic analysis with global and local imperfections included ("GNIA" method).

The influence of the change of joint stiffness in the steel frame calculation is neglected. There is a noticeable redistribution of bending moments in the calculation according to the GNIA in relation to the LA calculation.

It is evident from the calculation that the calculation of the elastic critical load factor $\alpha_{\text {cr }}$ is crucial for assessing the frame movability, which is directly related to the selection of the frame calculation procedure.

Efficient analysis of steel structures requires an adequate computer program that has the presented numerical models implemented. In addition to nonlinear analyses, linear analysis with dimensioning according to the standards is certainly recommended to be applied for practical engineering calculations and as a control calculation.

It is shown that the computer program [9] can be successfully used for calculations of steel frame structures according to EN 1993-1-1 [10], in which process it is possible to take into account initial global and local geometric imperfections. 
Markić, R., Ćubela, D., Mikulić, Ž.

Numerical model for analysis of steel frame structures with included geometric imperfections

\section{REFERENCES}

1. Bathe, K.J., Bolourchi, S.: Large displacement analysis of three-dimensional beam structures. International Journal for Numerical Methods in Engineering, 1979, 14, 961-986.

2. Goncalves, R., \& Camotim, D.: On the incorporation of equivalent member imperfections in the in-plane design of steel frames. Journal of Constructional Steel Research, 2005, 61, 1226-1240.

3. Mercier, C., Khelil, A., Khamisi, A., Al Mahmoud, F., Boissiere, R., Pamies, A.: Analysis of the global and local imperfections of structural members and frames. Journal of Civil Engineering and Management, 2019, 25(8), 805-818.

4. Kala, Z.: Geometrically non-linear finite element reliability analysis of steel plane frames with inital imperfections. Journal of Civile Engineering and Management, 2012, 18(1), 81-90.

5. Aguero, A., Pallares, L., \& Pallares, F. J.: Equivalent geometric imperfection definition in steel structures sensitive to flexural and/or torsional buckling due to compression. Engineering Structures, 2015, 96, 160-177.

6. Chladny, E., \& Štujberova, M.: Frames with unique global and local imperfection in the shape of the elastic buckling mode (Part 1). Stahlbau, 2013, 82(8), 609-617.

7. Chladny, E., \& Štujberova, M.: Frames with unique global and local imperfection in the shape of the elastic buckling mode (Part 2). Stahlbau, 2013, 82(9), 684-694.

8. Zdravkov, L.: Effective buckling lengths of compressed elements, determined by SAP 2000 and Robot Structural Analysis. 15th International scientific conference VSU'2015.

9. Autodesk Robot Structural Analysis Professional 2019, Autodesk Inc.

10. Eurocode 3: Design of steel structures - Part 1-1: General rules and rules for buildings (EN 1993-1-1:2005+AC:2009).

11. Eurocode 3: Design of steel structures - Part 1-8: Design of joints (EN 1993-18:2005+AC:2009).

12. Dujmović, D., Androić, B., Džeba, I.: Modeliranje konstrukcije prema Eurocode 3, I.A. Projektiranje, Zagreb 2004. 